\title{
A serine protease is involved in the initiation of DNA damage-induced apoptosis
}

\author{
EC de Bruin ${ }^{1}$, D Meersma ${ }^{1}$, J de Wilde ${ }^{1}$, I den Otter ${ }^{1}$, \\ EM Schipper ${ }^{1}$, JP Medema ${ }^{1,2}$ and LTC Peltenburg ${ }^{\star, 1,2}$ \\ 1 Department of Clinical Oncology, Leiden University Medical Center, Leiden, \\ The Netherlands \\ 2 JP Medema and LTC Peltenberg share senior authorship \\ * Corresponding author: LTC Peltenburg, Department of Clinical Oncology, \\ Leiden University Medical Center, PO Box 9600, 2300 RC Leiden, The \\ Netherlands. Tel.: + 3171526 4726/1890; Fax: + 3171526 6760; \\ E-mail: peltenburg@lumc.nl
}

Received 17.2.03; revised 09.5.03; accepted 30.5.03 Edited by RA Knight

\begin{abstract}
Caspases are considered to be the key effector proteases of apoptosis. Initiator caspases cleave and activate downstream executioner caspases, which are responsible for the degradation of numerous cellular substrates. We studied the role of caspases in apoptotic cell death of a human melanoma cell line. Surprisingly, the pancaspase inhibitor ZVAD-fmk was unable to block cleavage of poly(ADP-ribose) polymerase (PARP) after treatment with etoposide, while it did prevent DEVDase activity. It is highly unlikely that caspase-2, which is a relatively ZVAD-fmk-resistant caspase, is mediating etoposide-induced PARP cleavage, as a preferred inhibitor of this caspase could not prevent cleavage. In contrast, caspase activation and PARP degradation were blocked by pretreatment of the cells with the serine protease inhibitor 4-(2aminoethyl)benzenesulfonyl fluoride (AEBSF). We therefore conclude that a serine protease regulates an alternative initiation mechanism that leads to caspase activation and PARP cleavage. More importantly, while zVAD-fmk could not rescue melanoma cells from etoposide-induced death, the combination with AEBSF resulted in substantial protection. This indicates that this novel pathway fulfills a critical role in the execution of etoposide-induced programmed cell death.

Cell Death and Differentiation (2003) 10, 1204-1212. doi:10.1038/ sj.cdd.4401296
\end{abstract}

Keywords: apoptosis; serine protease; melanoma; PARP

\footnotetext{
Abbreviations: AEBSF, 4-(2-aminoethyl)benzenesulfonyl fluoride; AFC, 7-amino-4-trifluoromethyl-coumarin; CHAPS, 3-[(3-cholamidopropyl)dimethylammonio]-1-propanesulfonate; etop, etoposide, VP16; PARP, poly(ADP-ribose) polymerase-1; PBS, phosphate-buffered saline; PI, propidium iodide; PMSF, phenylmethylsulfonylfluoride; SDS, sodium dodecylsulfate; TNF $\alpha$, tumor necrosis factor $\alpha$; zVAD-fmk, benzyloxy-carbonyl-Val-AlaAsp-fluoromethyl ketone; zVDVAD-fmk, benzyloxycarbonyl-ValAsp-Val-Ala-Asp-fluoromethyl ketone
}

\section{Introduction}

Apoptosis is crucial for homeostasis and development in various organisms, whereas its inhibition via the accumulation of mutations is considered a prerequisite for the generation of malignant tumors. Apoptosis is executed by specialized proteases, called caspases, which cleave downstream caspases and numerous other cellular substrates. ${ }^{1}$ Two major pathways of apoptosis initiation have been described: the extrinsic and intrinsic pathways. The extrinsic pathway is used by death receptor ligands, for instance CD95 ligand or tumor necrosis factor $\alpha$ (TNF $\alpha$ ), which induce the activity of the initiator caspase $-8 .^{2}$ The intrinsic pathway is crucial for the induction of apoptosis by other types of stress, for example irradiation or chemotherapeutic drugs. These triggers lead to the release of apoptogenic factors, such as mitochondrial cytochrome $c$, into the cytosol. Released cytochrome $c$ complexes to Apaf-1 and caspase-9, inducing its oligomerization and activation in a so-called 'apoptosome'. ${ }^{3}$ Active caspase- 9 is capable of activating the executioner caspase3 , which in turn leads to the activation of other downstream caspases and the cleavage of cellular substrates.

However, caspase-9 and Apaf-1 are not essential for downstream caspase activity under all circumstances, because irradiated Apaf-1 or caspase- 9 null thymocytes still display residual DEVD and PARP cleavage activity. ${ }^{4}$ Moreover, cell death itself is only marginally affected in these 'apoptosome-deficient' cells, suggesting that an apoptosomeindependent caspase activation program exists. Apoptosis in the absence of the apoptosome appears to depend on caspase activity. Caspase- 1 and -7 are candidates for directly activated caspases that are upstream of or bypass mitochondria and employ the apoptosome merely to amplify the caspase cascade. ${ }^{4}$ In addition, caspase- 2 is recruited to a large protein complex in which it becomes active, and this process occurs in the absence of Apaf-1 oligomerization as well. $^{5}$ The role of caspase-2 in cell death upstream or downstream of the mitochondria is, however, greatly disputed. ${ }^{6}$ This is largely due to the fact that neither the actual activation nor the substrates have been identified.

Melanomas are characterized by early metastasis and extremely poor response to chemo- and radiotherapy. It is remarkable that p53 is rarely mutated in melanoma, ${ }^{7}$ while p53 mutations occur often in other aggressive and chemoresistant tumors. It has been proposed that the mechanism underlying melanoma resistance is the loss of Apaf-1 expression, as this mutation is commonly found in metastatic melanoma and correlates with resistance to the induction of an apoptotic program. ${ }^{8}$ Another explanation for melanoma resistance is the deregulation of the protein Survivin, a member of the inhibitor of apoptosis protein (IAP) family. This protein is strongly expressed in malignant melanoma ${ }^{9}$ and reported to bind to and inhibit effector caspase-3 and $-7,{ }^{10}$ although the direct effect on caspases has been questioned by other groups. ${ }^{11,12}$ Two other members of the IAP family, 
ML-IAP/Livin, ${ }^{13,14}$ and XIAP (LP, unpublished observations) are expressed at higher levels in melanoma cell lines than in normal melanocytes. Together, these observations suggest that the therapy resistance of melanomas is due to defects in the pathways downstream of or parallel to mitochondrial release.

Previously, we have shown that melanoma cell line IGR39D, which does not express functional p53, can be sensitized to diverse cell death triggers by expression of the cMyc oncoprotein (LP et al., submitted for publication). Activation of caspase-3, cleavage of PARP, DNA laddering and membrane blebbing indicate that this death occurs through an apoptotic process. In this report, we studied whether the pancaspase inhibitor zVAD-fmk could reverse the apoptotic program in these melanoma cells after triggering with DNA damage inducers or with the death receptor ligand TNF $\alpha$. Although zVAD-fmk effectively blocked the DEVDase activity after apoptotic treatment of these cells, no effect was observed on the classical caspase substrate PARP. This result suggests that a $Z V A D$-insensitive protease was able to induce the cleavage of PARP. Here, we describe a novel pathway that is induced upon several stress signals. This pathway is initiated by a serine protease that mediates the activation of downstream caspases and PARP cleavage.

\section{Materials and Methods}

\section{Cell lines}

The melanoma cell lines, neuroblastoma cell line IMR32 ${ }^{15}$ and the rat fibroblast cell line ${ }^{16}$ Rat-1/c-MycER ${ }^{\text {TM }}$ were cultured in DMEM supplemented with glutamine, penicillin/streptomycin and $8 \%$ heat-inactivated fetal calf serum at $37^{\circ} \mathrm{C}$. Human melanoma cell line IGR39D, its stable cmyc transfectant IGRmyc clone 3 (IGRmyc-3) and 603 are described elsewhere. ${ }^{17}{\text { Rat- }-1 / \mathrm{c}-M y c E R^{T M}}^{\text {TM }}$ cells were used in the absence of 4hydroxytamoxifen.

\section{Irradiation and other treatments}

Where indicated, exponentially growing cells were treated with $10 \mu \mathrm{g} / \mathrm{ml}$ etoposide (VP16, Bristol-Myers Squibb, New York, NY, USA) or $50 \mathrm{ng} / \mathrm{ml}$ TNF $\alpha$ (Boehringer Ingelheim, Germany) or ionizing radiation for the indicated time periods. Irradiation was performed in 9-cm dishes or six-well plates at room temperature using a 6-MV linear accelerator at a dose rate of $4 \mathrm{~Gy} / \mathrm{min}$. Doses were given in a single fraction of $8 \mathrm{~Gy}$. After irradiation, dishes were immediately returned to the incubator. Pretreatment with zVAD-fmk (Bachem, Bubendorf, Switzerland), zVDVAD-fmk (Enzyme Systems Products, Livermore, CA, USA) or AEBSF (Sigma) was performed for $60 \mathrm{~min}$ before application of the apoptotic triggers.

\section{Western blotting}

Adherent and nonadherent cells were collected together and washed twice with PBS. Whole-cell lysates were prepared by lysis of the cell pellets in cold lysis buffer consisting of $0.2 \mathrm{M}$ triethanolamine, $0.14 \mathrm{M} \mathrm{NaCl}, 0.5 \%$ NP-40, $0.2 \%$ sodiumdeoxycholate or in CHAPS lysis buffer, ${ }^{18}$ with freshly added $1 \mathrm{mM}$ PMSF and $1 \mathrm{mM}$ leupeptin. After clearing the lysate by highspeed centrifugation, protein concentrations were determined by a modified Bradford method. ${ }^{19}$ Equal amounts of total protein were resolved on SDS-PAGE gels and blotted on Hybond-P (Amersham, Uppsala,
Sweden). Ponceau S stainings were performed to verify protein quantities. Membranes were blocked with $5 \%$ nonfat dry milk in $20 \mathrm{mM}$ Tris- $\mathrm{HCl} \mathrm{pH}$ 7.6, $137 \mathrm{mM} \mathrm{NaCl}$ and $0.2 \%$ Tween-20 (TBS-T) for $1 \mathrm{~h}$. Primary antibody incubations were carried out in 1\% milk/TBS-T for $2 \mathrm{~h}$ and followed by three washes with TBS-T. Membranes were incubated with appropriate anti-mouse or anti-rabbit IgG horseradish peroxidase conjugates (Amersham) for $1 \mathrm{~h}$, washed three times and developed using ECLplus reagents (Amersham). The antibodies used were rabbit polyclonal antibodies recognizing human PARP (9542, New England Biolabs, Beverly, MA, USA) at 1: 3000 and cleaved human caspase-3 (9661, New England Biolabs) at $1: 1000$.

\section{Survival analyses}

Cell death was determined using propidium iodide (PI) uptake. For these experiments, floating and adherent cells were collected as described above. Cells were incubated for $5 \mathrm{~min}$ at room temperature with $1 \mathrm{mg} / \mathrm{ml} \mathrm{PI}$ in PBS containing $0.5 \% \mathrm{BSA}$ and $0.1 \%$ sodium azide. After this incubation, cells were analyzed for PI positivity on a FACScalibur ${ }^{\mathrm{R}}$ (BD-Biosciences, Erembodegem, Belgium). Cell survival was determined with clonogenic survival assays. Cells were treated with etoposide for $3 \mathrm{~h}$ in the absence or presence of the inhibitors $10 \mu \mathrm{M}$ zVAD-fmk and $200 \mu \mathrm{M}$ AEBSF. Culture medium was refreshed and the cells were incubated for 1 week with or without inhibitors. Cells were washed, fixed and stained with 5\% Giemsa stain.

\section{Substrate cleavage assays}

For the DEVD and VDVAD cleavage assays, lysates were prepared from pooled adherent and nonadherent cells in CHAPS lysis buffer. ${ }^{18}$ Caspase activity in these samples was assayed by measuring the release of 7amino-4-trifluoromethyl-coumarin (AFC) from DEVD- or VDVAD-containing peptides. ${ }^{18,20}$

The in vitro PARP cleavage assays were performed by incubating 20ng aliquots of recombinant human PARP (Alexis, Montreal, Canada) in caspase cleavage buffer ${ }^{18}$ for $1.5 \mathrm{~h}$ at $30^{\circ} \mathrm{C}$ with increasing concentrations of recombinant human caspase-3 or caspase-2 (R\&D Systems, Minneapolis, MN, USA) in the presence or absence of $1 \mu \mathrm{l} 10 \mathrm{mM}$ DEVD-AFC or VDVAD-AFC peptide, respectively. The release of AFC in the AFC-containing reactions was measured in a multilabel counter ${ }^{18}$ and the cleavage of the added PARP in the matching reactions was determined by Western blotting.

\section{Results}

\section{Etoposide-induced PARP cleavage in melanoma cells occurs independently of ZVAD-fmk-sensitive caspases}

We have previously shown that treatment of melanoma cell line IGRmyc-3 with various DNA-damaging triggers, ER stress inducers, heat shock or $\mathrm{TNF} \alpha$ leads to the onset of an apoptotic program characterized by activation of caspase-3 and cleavage of its substrate PARP (LP et al., submitted for publication). To establish whether a pancaspase inhibitor could rescue these cells from DNA damage-induced apoptosis, we pretreated the cells with ZVAD-fmk and measured PARP cleavage and DEVDase activity. Although all caspases are able to cleave DEVD-afc to some extent, it is the preferred substrate of caspase- 3 and -7 , which can both cleave PARP. ${ }^{21-23}$ Surprisingly, we observed that etoposide-induced PARP cleavage could not be inhibited with $10 \mu \mathrm{M}$ zVAD-fmk, as analyzed 
by Western blotting (Figure 1a). In the untreated cell cultures, there are always some dying cells because of general culture stress, resulting in some cleavage of PARP in the control samples. Cell detachment and membrane blebbing, as visualized by microscopy, confirmed that the cells demonstrated characteristics of an apoptotic process in the presence of zVAD-fmk (Figure 1b). To confirm that the inhibitor was indeed functional under these conditions, we measured DEVDase activity and observed a complete inhibition when the cells were pretreated with $10 \mu \mathrm{M}$ zVAD-fmk

a

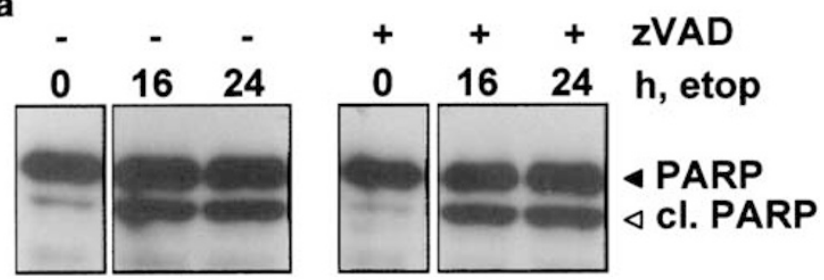

b
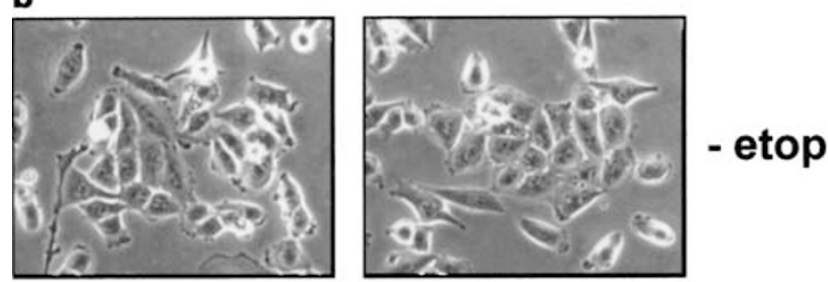

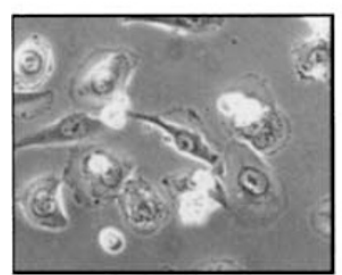

- zVAD

C

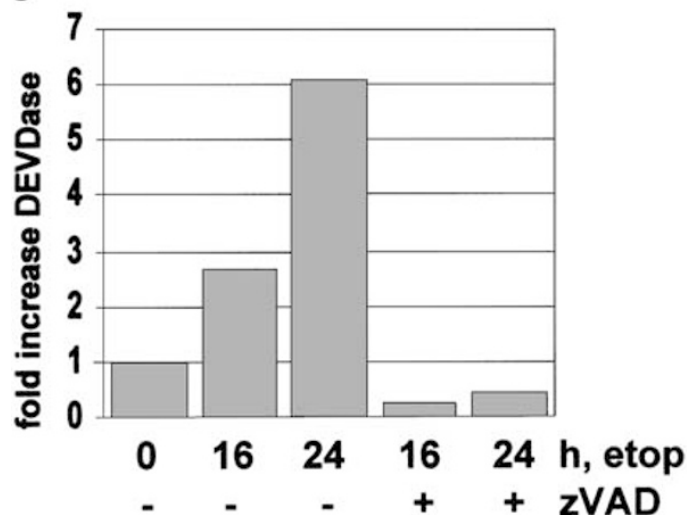

Figure 1 The pancaspase inhibitor zVAD-fmk blocks DEVDase activity, but cannot block DNA damage-induced apoptosis. (a) IGRmyc-3 cells were treated with etoposide in the absence or presence of $10 \mu \mathrm{M}$ zVAD-fmk. Whole-cell lysates were prepared at the indicated time points and PARP cleavage was determined on Western blot using a rabbit polyclonal antibody. (b) IGRmyc-3 cells were photographed under a phase-contrast microscope at $\times 200$ magnification after treatment for $24 \mathrm{~h}$ with etoposide and/or $10 \mu \mathrm{M}$ zVAD-fmk or left untreated as indicated. (c) DEVDase activity was measured in DEVD-AFC cleavage assays using $10 \mu \mathrm{g}$ of protein from lysates of IGRmyc-3 at the indicated time points after treatment with etoposide in the absence or presence of $10 \mu \mathrm{M}$ zVAD-fmk. The figure is representative of three independent experiments
(Figure 1c). Similar data were obtained when these cells were treated with irradiation (data not shown), suggesting that this human melanoma cell line dies by an apoptotic program that is independent of DEVDase activity. Moreover, PARP cleavage occurs at least to a large extent by a zVADfmk-insensitive protease under these conditions.

\section{Caspase-2 is not responsible for the cleavage of PARP}

Caspase-2 has been reported to be fairly insensitive to zVAD-fmk. ${ }^{24}$ Since caspase-2 is suggested to cleave PARP ${ }^{25}$ and can act as an initiator caspase ${ }^{26}$ we analyzed whether caspase-2 is responsible for PARP cleavage in this melanoma cell line using several strategies. First, we determined the ability of recombinant active caspase-2 to cleave recombinant PARP by in vitro incubation. As expected, control incubations of PARP with active recombinant caspase-3 resulted in effective processing of PARP even at low concentrations of the enzyme. However, to our surprise, caspase-2 was unable to cleave PARP in vitro under the same conditions, while at the same time processing of the VDVAD substrate under the same conditions was clearly observed (Figure 2a). This experiment indicates that recombinant caspase-2 is not a PARPase in vitro, yet does not exclude a role for caspase-2 in etoposide-induced PARP cleavage in vivo. To analyze the involvement of caspase-2 further, we blocked caspase-2 activity in vivo by using the inhibitor ZVDVAD-fmk which is able to inhibit caspase-2, -3 and -7 with similar efficiencies. ${ }^{23}$ Consistent with the data in Figure $2 \mathrm{a}$, pretreatment of the cells with increasing concentrations, up to $50 \mu \mathrm{M}$, of zVDVAD-fmk did not reduce etoposide-induced PARP cleavage (Figure $2 b$, upper panel). The VDVADase activity, which might represent activation of caspase-2 as well as caspase- 3 and -7 , in these cells was significantly inhibited, even at the lowest concentration of zVDVAD-fmk (Figure 2b, lower panel). Moreover, pretreatment of the cells with $10 \mu \mathrm{M}$ zVAD-fmk, the pancaspase inhibitor that was unable to prevent PARP cleavage, resulted in a complete block of the VDVADase activity (Figure 2c). This suggests that either caspase-2 is sensitive to this concentration of zVAD-fmk or that the VDVADase activity measured in these cells reflects the activity of other caspases. These experiments thus make it very unlikely that caspase-2 plays a role in PARP cleavage in this cell line.

\section{A serine protease inhibitor abolishes DNA damage-induced apoptosis}

As etoposide-induced PARP cleavage in the human melanoma cell line IGRmyc-3 appears caspase-independent, we hypothesized that a distinct protease is responsible for the cleavage of cellular substrates. Therefore, these cells were pretreated with the potent serine protease inhibitor 4-(2aminoethyl)benzenesulfonyl fluoride (AEBSF), which acts by sulfonylation of the serine residue at the active site. ${ }^{27}$ We monitored the appearance of the cleaved PARP fragment on Western blots. In contrast to ZVAD-fmk, pretreatment with AEBSF prevented etoposide-induced cleavage of PARP (Figure 3a, upper panel), suggesting that a serine protease is involved in the cascade that leads to PARP processing. Importantly, the observed etoposide-induced PARP cleavage is not due to postlysis effects, but occurs in intact cells as cell lysates prepared by immediate boiling in SDS buffer display identical levels of PARP cleavage (data not shown).

Activation of caspase- 3 is achieved through a two-step process. The first cleavage results in p12 and p20 subunits, while the second step is a further processing of this p20 subunit to the p17 subunit. ${ }^{28}$ The latter 
a

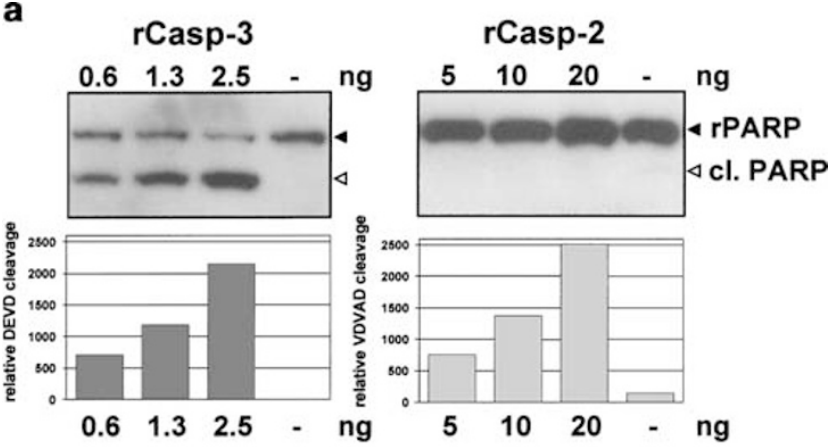

b
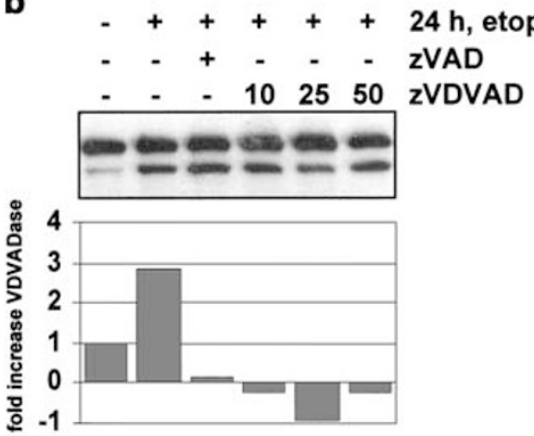

C

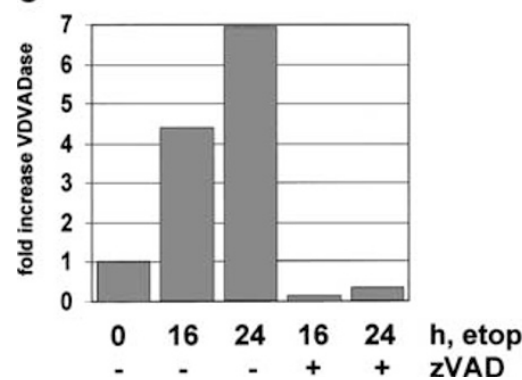

Figure 2 Caspase-2 is not responsible for the PARP cleavage observed during etoposide-induced apoptosis. (a) 20-ng aliquots of recombinant human PARP were incubated in caspase cleavage buffer with increasing concentrations of active recombinant human caspase- 3 or -2 as indicated. Cleavage of PARP was determined on Western blot. In matching reactions, the caspase-3 and -2 activity was measured using DEVD-AFC or VDVAD-AFC, respectively. (b) IGRmyc-3 cells were left untreated $(-)$ or treated $(+)$ with etoposide for $24 \mathrm{~h}$ in the absence or presence of $10 \mu \mathrm{M} z \mathrm{VAD}$-fmk or of the indicated concentrations of zVDVAD-fmk $(\mu \mathrm{M})$. CHAPS cell lysates were prepared and PARP cleavage was determined by Western blotting. VDVDADase activity in the same lysates was determined using the AFC-labelled substrate. (c) VDVADase activity was measured in VDVAD cleavage assays of lysates prepared from IGRmyc-3 cells after treatment with etoposide for the indicated time periods in the absence or presence of $10 \mu \mathrm{M}$ zVAD-fmk. The figure is representative for three independent experiments

cleavage, known to be mediated by caspase- 3 itself, is blocked when the melanoma cells are pretreated with zVAD-fmk (Figure 3a, lower panel). This result underscores the observation that ZVAD-fmk prevented caspase activity, because it blocked autoprocessing to the p17 subunit in our system (Figure 1c). Nevertheless, we did observe the appearance of the p20 subunit indicating that the initial cleavage of caspase-3 occurred in the presence of a pancaspase inhibitor in these cells (Figure 3a). Interestingly, the serine protease inhibitor AEBSF also blocked this initial caspase-3 processing (Figure 3a) and DEVDase activity (Figure 3c, left), and thus seems to act upstream of caspase-3 activation.

To determine whether the protective effect of AEBSF was restricted to etoposide-induced apoptosis, we treated these cells with irradiation. Irradiation-induced PARP cleavage in these melanoma cells could be prevented by AEBSF (Figure $3 \mathrm{~b}$, upper panel). Cleavage of PARP triggered by the ER stress inducer Brefeldin A could also be partially blocked (data not shown), suggesting that the involvement of a serine protease in the apoptotic process is not limited to DNA damage-induced apoptosis. On the other hand, cleavage of PARP and caspase- 3 caused by the death receptor ligand TNF $\alpha$ could not be inhibited by AEBSF (Figure $3 \mathrm{~b}$, lower panel). In agreement with this finding, DEVDase activity induced by TNF $\alpha$ was insensitive to AEBSF (Figure 3c, right). This result confirmed the observation that AEBSF is not a general inhibitor of caspases. ${ }^{29,30}$ In agreement, when added directly to the lysates or to recombinant caspase-3, AEBSF was not able to inhibit the DEVDase activity in vitro, in contrast to ZVAD-fmk (data not shown). These results indicate that the DEVDase activity in these cells is inhibited indirectly by AEBSF and suggests that AEBSF acts upstream of caspase-3.

\section{Inhibition of serine protease and caspase activity rescues etoposide-treated cells}

Activation of caspases and cleavage of several caspase substrates are intrinsic to the execution of apoptosis. However, inhibition of these events using caspase inhibitors does not always lead to the protection from death. ${ }^{31-34}$ Also here we find that etoposide-induced blebbing of the melanoma cell was hardly affected by addition of zVAD-fmk. The observation that a serine protease acts upstream of caspase activation may explain this phenotype as this protease activity may circumvent the need for caspase activity and still effectively induce cell death. To analyze the effects on cell death in more detail, we therefore set out to determine the membrane integrity of the melanoma cells upon treatment with etoposide. We measured the capacity of the treated cells to exclude PI. Etoposide induced clear loss of membrane integrity already after $16 \mathrm{~h}$ (data not shown) and this loss increased over time. At $24 \mathrm{~h}, \mathrm{PI}$ uptake amounted to $33 \%$ over background and to $46 \%$ at $32 \mathrm{~h}$. Importantly, zVAD-fmk pretreatment had the capacity to initially prevent this cell death to some extent, but this effect was lost at later time points, suggesting that the inhibition of caspase activity by zVAD-fmk is not sufficient to prevent cell death. We also analyzed the effect of AEBSF pretreatment on cell survival. Unfortunately, this analysis was hampered by the fact that AEBSF itself showed some toxicity, especially at higher concentrations (10-20\% cell death). We therefore decided to use declining concentrations of AEBSF to circumvent this side effect. Treatment of cell with $100 \mu \mathrm{M}$ AEBSF resulted only in marginal toxic effects (5-10\% cell death). Nevertheless, this concentration of AEBSF already significantly protected the cells from etoposide-induced death (Figure 3D). This effect increased steadily with increasing concentrations of AEBSF. More importantly, zVAD-fmk together with AEBSF clearly displayed an additive effect. The combination of zVAD-fmk with $100 \mu \mathrm{M}$ AEBSF almost completely blocked PI uptake, which was back to background levels when zVAD-fmk was used together with $200 \mu \mathrm{M}$ AEBSF, even at $32 \mathrm{~h}$ (Figure $3 \mathrm{~d}$ ).

These data thus suggest that AEBSF in concert with zVAD-fmk can induce survival. In order to determine whether etoposide-treated cells would indeed survive for longer periods of time, we performed clonogenic survival assays. Cells were treated with etoposide in the absence or presence of the inhibitors. After 1 week of incubation, hardly any cells were observed in the etoposide-treated sample, indicating that almost all had 
a
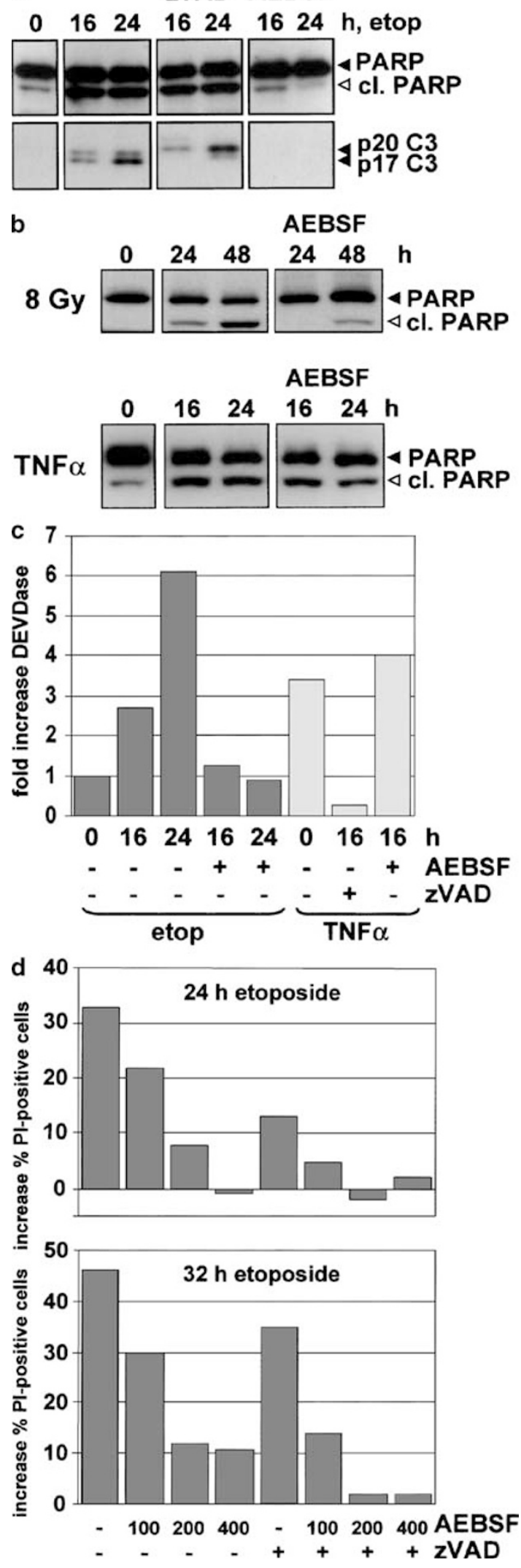

succumbed to the toxic effects of etoposide (Figure 3e). The addition of $10 \mu \mathrm{M}$ zVAD-fmk could not permanently rescue the cells. Even though after shorter periods $200 \mu \mathrm{M}$ AEBSF could protect the cells against etoposide (Figure $3 \mathrm{~d}$ ), at later time points this protection was no longer observed. This suggests that the toxic effect of AEBSF prohibits the longterm survival. However, incubation of the cells in the presence of both inhibitors resulted in the appearance of many small colonies, suggesting that these cells do not only survive but also regain their proliferative capacity. Of course, the amount of cells seen in the wells is far less as in the untreated samples as the latter ones have not experienced the DNAdamaging effects of etoposide and thus did not need to repair the damage before cycling (Figure 3e, left panel). Moreover, an effect of AEBSF on the cell cycle has been reported as well (Stefanis et al. ${ }^{40}$ and data not shown). Nevertheless, as small colonies are observed, the long-term effect of the combined inhibitors clearly permits continuing proliferation of the cells (Figure 3e).

These results indicate that inhibition of the serine protease activity in combination with inhibition of caspases is sufficient to extend survival of these melanoma cells for longer time periods after treatment with the potent cytotoxic drug etoposide.

\section{AEBSF prevents apoptosis in several cell types}

To establish whether etoposide-induced PARP cleavage in other melanoma cell lines can be abolished by pretreatment with AEBSF, we analyzed the cleavage of PARP in IGR39D, the parental cell line of IGRmyc-3, and in melanoma cell line 603, which also shows some sensitivity to etoposide (Figure 4a). The protective effect of AEBSF was not restricted to IGRmyc-3, as this inhibitor could prevent PARP cleavage in the parental cell line IGR39D as well. However, it is clear that the effect of AEBSF was not found in all cell lines, as AEBSF failed to inhibit PARP cleavage in the less susceptible melanoma cell line 603. Importantly, we also found that etoposide-induced PARP cleavage in the human neuroblastoma cell line IMR32 could be blocked by AEBSF (Figure 4a), indicating that the protective effect of AEBSF is not limited to melanoma cells.

Figure 3 Serine protease inhibitor AEBSF blocks DNA damage-induced apoptosis, but not TNF $\alpha$-triggered apoptosis. (a) Western blot of whole-cell lysates of IGRmyc-3 cells, harvested at the indicated time points after addition of etoposide. Cells were treated in the absence or presence of $10 \mu \mathrm{M} \mathrm{zVAD-fmk} \mathrm{or}$ $400 \mu \mathrm{M}$ AEBSF. The upper part was incubated with an antibody recognizing fulllength and cleaved PARP and the lower part with an antibody specific for cleaved caspase-3. The p20 and p17 subunits are marked. (b) IGRmyc-3 cells were irradiated with 8 Gy or treated with TNF $\alpha$ as indicated. Full-length PARP $(\varangle)$ and cleaved PARP $(\triangleleft)$ were determined by Western blotting. (c) DEVDase activity was determined using the substrate DEVD-AFC. The left part is representative for three independent experiments of treatment of IGRmyc-3 cells with etoposide for the indicated time periods with or without pretreatment of $400 \mu \mathrm{M}$ AEBSF. The right part represents IGRmyc-3 cells treated with $\mathrm{TNF} \alpha$ for $16 \mathrm{~h}$ either without pretreatment, or pretreated with $10 \mu \mathrm{M}$ zVAD-fmk or $400 \mu \mathrm{M}$ AEBSF. The graph is representative for at least two independent experiments. (d) IGRmyc-3 cells were left untreated or treated with etoposide in the presence or absence of increasing concentrations of AEBSF $(\mu \mathrm{M})$ and/or $10 \mu \mathrm{M}$ zVAD-fmk for 24 or $32 \mathrm{~h}$, as indicated. The percentage of cells that failed to exclude PI was determined by FACS analysis. The percentages of PI-positive untreated cells were 17 and $14 \%$ at 24 and $32 \mathrm{~h}$, respectively. The background percentages of PI-positive cells cultured in the absence of etoposide were subtracted from the corresponding etoposide-treated samples. (e) IGRmyc cells were treated with etoposide in the absence or presence of the indicated inhibitors. After $3 \mathrm{~h}$, the medium and inhibitors were refreshed and cells were incubated for 1 week. Cells were visualized by staining with Giemsa solution. The left panel shows photographs of the cells, cultured in six-well plates. The right panel shows microscopic pictures of the same cell cultures at $\times 50$ magnification 


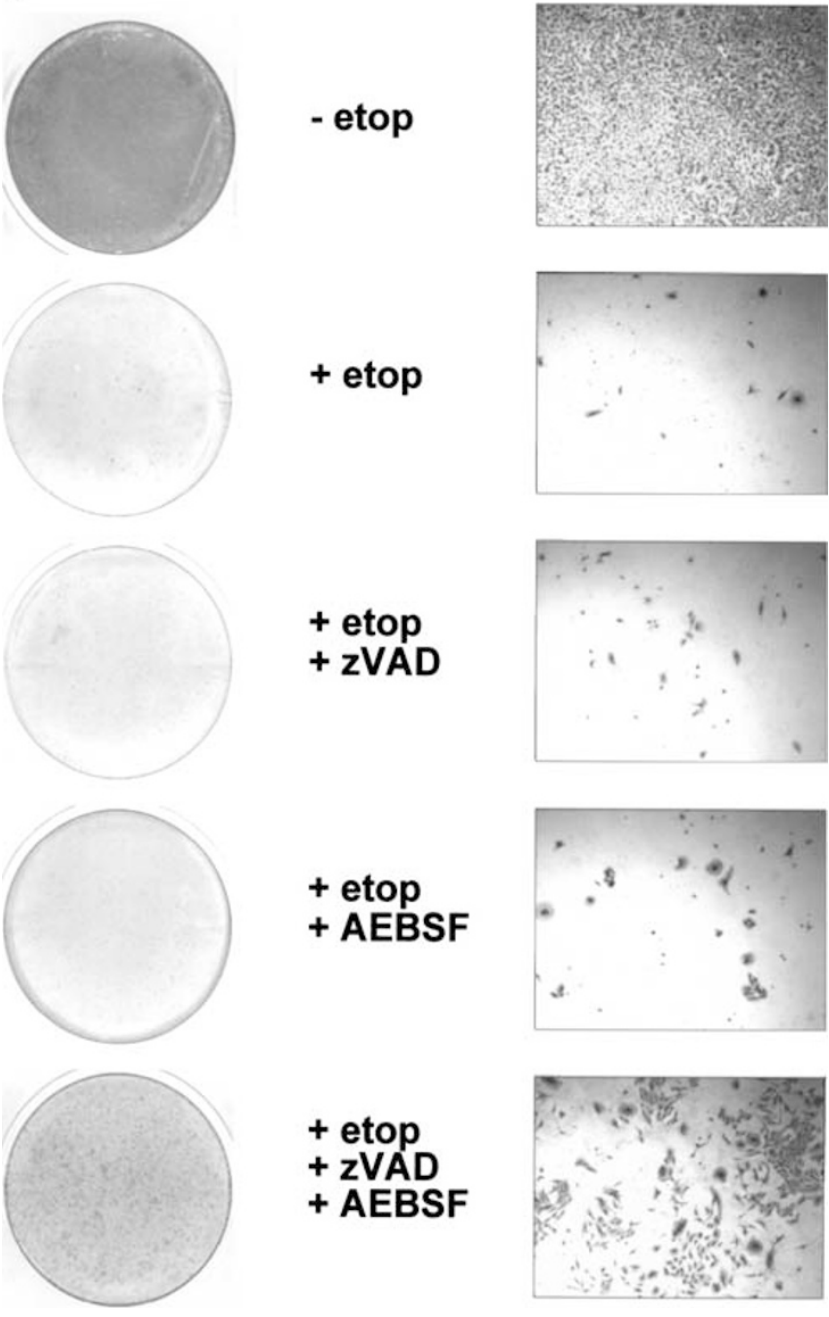

Figure 3 (continued)

In addition, we determined whether substrate cleavage and caspase activation in a rat fibroblast-derived cell line could be blocked by pretreatment with AEBSF. Analysis of etoposide-treated rat fibroblasts demonstrated that PARP cleavage as well as DEVDase activity were completely blocked by this serine protease inhibitor (Figure $4 b)$. Together, these data indicate that a serine protease plays an important role in DNA damage-induced apoptosis in various cell types.

\section{Discussion}

\section{Caspase-independent initiation of apoptosis}

In this study, we characterized certain proteolytic events that are responsible for apoptotic cell death induced by DNA damage in human melanoma cells. In IGRmyc-3 cells, caspase-3 is processed and activated during apoptosis. As expected, DEVDase activity was abolished by pretreatment with the pancaspase inhibitor ZVAD-fmk. Nevertheless, these zVAD-fmk-treated cells still demonstrated membrane blebbing, which has been reported previously. ${ }^{31}$ Intriguingly, we found that in the absence of DEVDase activity, PARP was still cleaved into a fragment of approximately $85 \mathrm{kDa}$, a phenomenon that to our knowledge has never been reported before. Only in the case of necrosis in Jurkat cells, PARP is processed in the presence of ZVAD-fmk, but this processing results in other fragments than we observed in this study. ${ }^{35}$ Therefore, the question is raised as to which protease was responsible for the observed PARP cleavage.

It has been reported that in COS cells overexpression of caspase-2, which is proposed to be relatively zVAD fmk-insensitive, ${ }^{24}$ leads to cleavage of PARP. ${ }^{25}$ Recent studies demonstrate caspase-2 as an initiator caspase upstream of the mitochondria. ${ }^{26,36,37}$ However, we provide evidence that indicates that caspase-2 is not responsible for initiating the apoptotic program in IGRmyc-3 cells. Whereas VDVADase activity, reflecting the activity of caspase- $-2,-3$ and -7 , was blocked by pretreatment with $z$ VDVAD-fmk, ${ }^{23}$ this inhibitor did not affect the etoposide-induced cleavage of PARP. Furthermore, we demonstrated that zVAD-fmk was able to block the zVDVADase activity, suggesting that caspase-2 is either sensitive to the concentration of zVAD-fmk we used or that the zVDVADase activity in these cells does not reflect the activity of caspase-2, but the activity of caspase- 3 or -7 . Therefore, we exclude a role for caspase-2 in PARP cleavage in etoposide-treated IGRmyc-3 cells. Our observations are in agreement with O'Reilly et al., ${ }^{38}$ who concluded that caspase-2 is not essential for apoptosis in all cell types, because thymocytes and neuronal cells derived from caspase-2-deficient mice die normally in response to a broad range of apoptotic stimuli. Despite these data, a definite exclusive answer on the role of caspase- 2 cannot be given as both the mode of activation and the identity of physiological active caspase-2 are unknown. Like other initiator caspases, caspase-2 may be activated by induced proximity. Whether such a caspase-2 apoptosome displays different substrate specificity compared to cleaved caspase-2 product will need to be determined and an effect of AEBSF on this activity is at this point pure speculation but cannot be formally excluded.

Another initiator caspase, caspase-9, is also very unlikely to be the PARPase in our system, as the etoposide-induced LEHDase activity is completely blocked by zVAD-fmk pretreatment (data not shown). We therefore suggest that the apoptotic pathway in IGRmyc-3 can be initiated independently of caspase activity.

\section{Involvement of a serine protease in apoptotic cell death}

There are several indications that the mitochondrial pathway is not functional in IGRmyc-3 cells. It has been proposed that melanoma cells often exhibit downregulated Apaf-1 expression, leading to a defect in the apoptotic pathway downstream of the mitochondria and resistance of the cells to apoptosis-inducing triggers. ${ }^{8}$ Although the Apaf- 1 expression in IGRmyc-3 is not downregulated as compared to melanocytes, the expression of caspase- 9 is relatively low and there is abundant expression of XIAP (unpublished observations). In line with these observations, we were unable to substantiate a role for cytochrome $c$ release and the activity of the apoptosome during DNA damage-induced apoptosis in IGRmyc-3 melanoma cells (unpublished observations), suggesting that the mitochondrial pathway is not involved in these cells. Interestingly, Marsden et al. ${ }^{4}$ recently demonstrated that apoptosis is only slightly delayed in Apaf-1- and caspase-9-deficient cells and conclude that in these cells, the apoptosome is not essential for apoptosis. The lack of involvement of the apoptosome pathway in the initiation of DNA damageinduced apoptosis in IGRmyc-3 cells leads us to hypothesize that, in these cells, apoptosis is mediated by an alternative pathway. This study supports this hypothesis, demonstrating that pretreatment with the serine protease inhibitor AEBSF affected the first cleavage step of caspase-3 activation and the cleavage of PARP induced by DNA-damaging agents. Moreover, in combination with zVAD-fmk, AEBSF rescued these cells from etoposide-induced death and even allowed clonogenicity. 
a

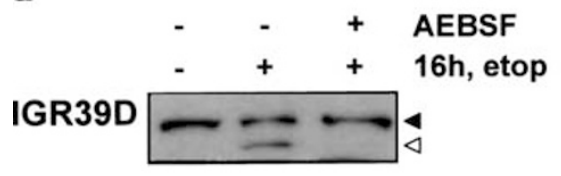

603

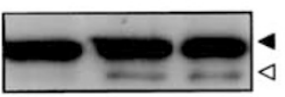

IMR32

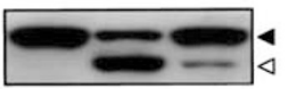

b

\section{Rat fibroblasts}
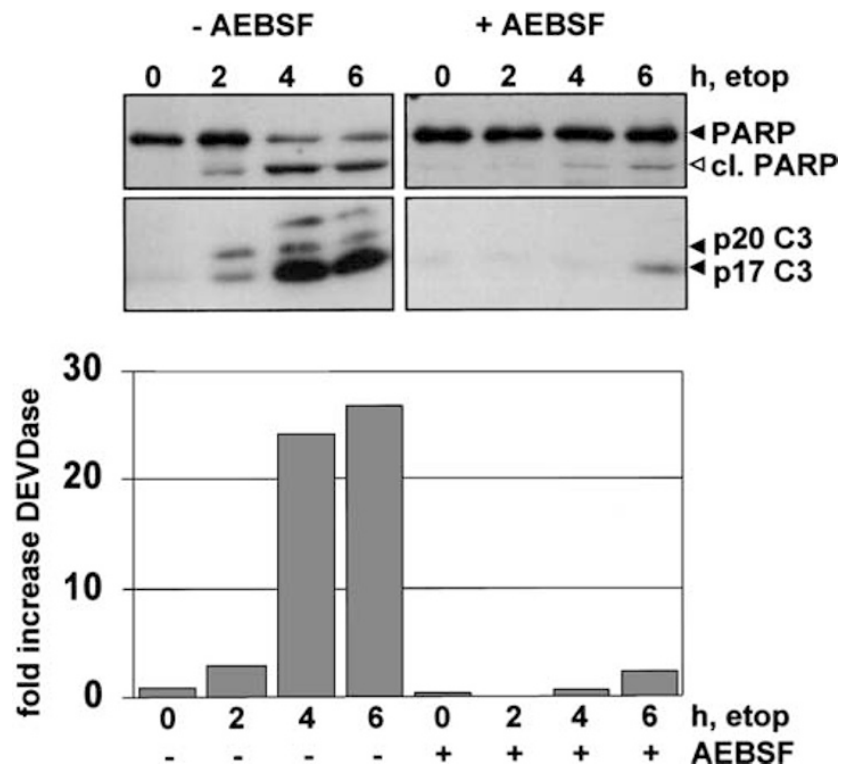

Figure 4 AEBSF inhibits apoptosis in several cell types. (a) The human melanoma cell lines IGR39D and 603 and the neuroblastoma cell line IMR32 were left untreated or treated with etoposide for $16 \mathrm{~h}$ in the absence or presence of $400 \mu \mathrm{M}$ AEBSF. Whole-cell lysates were analyzed on Western blot. Full-length PARP $(\varangle)$ and cleaved PARP $(\triangleleft)$ are marked. (b) Rat fibroblast-derived cells were treated with etoposide with or without pretreatment with $400 \mu \mathrm{M}$ AEBSF and lysed in CHAPS buffer at the indicated time points. Cleavage of PARP was determined by Western blotting. DEVDase activity in the same rat fibroblast lysates was determined using the substrate DEVD-AFC

Based on the observation that AEBSF could not rescue IGRmyc-3 from TNF $\alpha$-induced apoptosis, we conclude that the serine protease is not essential for at least this, and possibly other forms of, death receptortriggered apoptosis. AEBSF is therefore not a general inhibitor of caspases or of apoptotic manifestations. This result is in agreement with previous observations that AEBSF can inhibit Bin-1-mediated apoptosis, but fails to block apoptosis induced by Fas activation, granzyme $B{ }^{29}$ or staurosporin. ${ }^{30}$ In contrast, TNF $\alpha$-induced apoptosis of human gastric adenocarcinoma cells is inhibited by AEBSF, ${ }^{39}$ suggesting that the effect of AEBSF is cell line dependent.

Importantly, the activation of apoptosis by an AEBSF-sensitive serine protease is not restricted to IGRmyc-3, a melanoma line that is sensitized by c-Myc. Similar observations were made in the parental, nontransfected cell line IGR39D. Moreover, the neuroblastoma cell line IMR32 and a rat fibroblast line were also shown to be protected from etoposide-induced PARP cleavage and DEVDase activity by AEBSF. Nevertheless, AEBSF- induced protection is cell line dependent, as another melanoma line failed to show inhibition of their apoptotic program. Clarification of the cell type specificity of this inhibition could yield crucial insight into the mechanism of serine protease-induced apoptosis.

The suppression of cell death by AEBSF has been described in earlier publications, in which the AEBSF-sensitive serine protease is placed upstream of caspase activity. ${ }^{29,39-42}$ The inhibition of apoptotic features ${ }^{29,39}$ and the cleavage of PARP by PC12 lysates ${ }^{40}$ is suggested to be the result of blocking caspases by AEBSF or via inhibition of the function of $p 53 .{ }^{42}$ We, however, demonstrated that PARP is cleaved in the absence of DEVDase activity and functional p53. AEBSF is able to block both the DEVDase activity and the cleavage of PARP. We therefore suggest that AEBSF blocks a serine protease that functions upstream of caspases and can also bypass the zVAD-sensitive caspases in the cleavage of PARP. More importantly, we show that this pathway is highly relevant for melanoma cell death induced by several treatments as its incidence kills cells effectively independently of caspases, while its absence allows the cells to survive. As such, a better understanding of this protease may provide new effective ways to treat tumors.

\section{Alternative death pathways}

Several protease activities, other than caspases, have been implicated during apoptosis in different systems. For example, cathepsins and calpains, which are cysteine proteases (reviewed by Leist and Jaattela ${ }^{43}$ ), and the serine proteases Granzyme B and HtrA2/Omi have been shown to modulate or even initiate an apoptotic cascade. In some cell types, release of cathepsin B from the lysosomal compartment is critically important for TNF $\alpha$-induced apoptosis. ${ }^{44,45}$ Once released, cathepsin B activates the caspase machinery, followed by the induction of cell death. Importantly, this pathway can be inhibited effectively using $\mathrm{CA}-074 \mathrm{Me},{ }^{46}$ a highly specific cathepsin B inhibitor. This observation prompted us to determine whether cathepsin $B$ was the protease involved in our melanoma system. However, CA-074Me failed to reduce etoposide-induced PARP cleavage in our cells (unpublished observations), suggesting that another protease mediates this cleavage.

Granzyme B, which can induce cell death via cleavage of Bid and caspase-3, -7 and $-8,{ }^{47-50}$ is not expressed by these cells. Waterhouse et al. ${ }^{51}$ previously described a role for calpain in irradiation-induced apoptosis and suggested that activation of this protease leads to cleavage of fodrin as well as caspases. We attempted to analyze the effect of the conventional calpain inhibitor $1^{52}$ in our system, but the inhibitor had severe toxic side effects on the melanoma cells (data not shown). This result clearly indicates an important role for calpains in survival, but on the other hand does not exclude a role for calpain activity in apoptosis.

The serine protease HtrA2 is released from the mitochondria during apoptosis and sequesters XIAP, thereby allowing caspase activation to occur. Besides its XIAP-binding activity, HtrA2 contains a serine protease activity that by itself can induce cell death. ${ }^{53-56}$ Although these findings would propose $\mathrm{HtrA} 2$ as a candidate apoptogenic molecule, transfection experiments with full-length as well as processed HtrA2 in IGRmyc-3 indicated that overexpression of this protease did not induce nor accelerate cell death in these melanoma cells (unpublished observations). Taken together, these data point to the presence of yet another serine protease activity, inhibition of which rescues from apoptotic cell death, but formal proof for this idea will be provided by the identification of the protease involved. We are currently pursuing this question.

In conclusion, our data demonstrate that an AEBSF-sensitive protease is central to the initiation of apoptosis in several cell types. This protease might be placed on top of the caspase activation cascade and regulates 
the cleavage of PARP independently of caspases. Although the exact mechanism by which this protease mediates cell death remains to be determined, our data provide convincing evidence for an alternative pathway by which cells can undergo apoptosis.

\section{Acknowledgements}

We thank René Medema for providing the rat fibroblasts, Bob van de Water, Arnoud van der Laarse and Merlijn Bazuine for reagents, and Jennifer Rohn and Corrie Marijnen for critical reading of this manuscript. This work was supported by grants from the Vanderes Foundation, the J.A. Cohen Institute, the Dutch Science Organization and the Foundation Clinical Oncology Leiden.

\section{References}

1. Thornberry NA and Lazebnik Y (1998) Caspases: enemies within. Science 281 1312-1316

2. Ashkenazi A and Dixit VM (1998) Death receptors: signaling and modulation. Science 281: 1305-1308

3. Cain K, Bratton SB, Langlais C, Walker G, Brown DG, Sun XM and Cohen GM (2000) Apaf-1 oligomerizes into biologically active approximately $700-\mathrm{kDa}$ and inactive approximately 1.4-MDa apoptosome complexes. J. Biol. Chem. 275: 6067-6070

4. Marsden VS, O'Connor L, O'Reilly LA, Silke J, Metcalf D, Ekert PG, Huang DC, Cecconi F, Kuida K, Tomaselli KJ, Roy S, Nicholson DW, Vaux DL, Bouillet P, Adams JM and Strasser A (2002) Apoptosis initiated by Bcl-2-regulated caspase activation independently of the cytochrome c/Apaf-1/caspase-9 apoptosome. Nature 419: 634-637

5. Read SH, Baliga BC, Ekert PG, Vaux DL and Kumar S (2002) A novel Apaf-1independent putative caspase-2 activation complex. J. Cell. Biol. 159: 739-745

6. Troy CM and Shelanski ML (2003) Caspase-2 redux. Cell Death. Differ. 10: 101-107

7. Zerp SF, Van Elsas A, Peltenburg LTC and Schrier PI (1999) p53 mutations in human cutaneous melanoma correlate with sun exposure but are not always involved in melanomagenesis. Br. J. Cancer 79: 921-926

8. Soengas MS, Capodieci P, Polsky D, Mora J, Esteller M, Opitz-Araya X, McCombie R, Herman JG, Gerald WL, Lazebnik YA, Cordon-Cardo C and Lowe SW (2001) Inactivation of the apoptosis effector Apaf-1 in malignant melanoma. Nature 409: 207-211

9. Grossman D, McNiff JM, Li F and Altieri DC (1999) Expression and targeting of the apoptosis inhibitor, survivin, in human melanoma. J. Invest. Dermatol. 113 1076-1081

10. Tamm I, Wang Y, Sausville E, Scudiero DA, Vigna N, Oltersdorf T and Reed JC (1998) IAP-family protein survivin inhibits caspase activity and apoptosis induced by Fas (CD95), Bax, caspases, and anticancer drugs. Cancer Res. 58 : $5315-5320$

11. Banks DP, Plescia J, Altieri DC, Chen J, Rosenberg SH, Zhang $\mathrm{H}$ and $\mathrm{Ng} \mathrm{SC}$ (2000) Survivin does not inhibit caspase-3 activity. Blood 96: 4002-4003

12. Verdecia MA, Huang H, Dutil E, Kaiser DA, Hunter T and Noel JP (2000) Structure of the human anti-apoptotic protein survivin reveals a dimeric arrangement. Nat. Struct. Biol. 7: 602-608

13. Vucic D, Stennicke HR, Pisabarro MT, Salvesen GS and Dixit VM (2000) MLIAP, a novel inhibitor of apoptosis that is preferentially expressed in human melanomas. Curr. Biol. 10: 1359-1366

14. Kasof GM and Gomes BC (2001) Livin, a novel inhibitor of apoptosis protein family member. J. Biol. Chem. 276: 3238-3246

15. Tumilowicz JJ, Nichols WW, Cholon JJ and Greene AE (1970) Definition of a continuous human cell line derived from neuroblastoma. Cancer Res. 30: $2110-2118$

16. Littlewood TD, Hancock DC, Danielian PS, Parker MG and Evan GI (1995) A modified oestrogen receptor ligand-binding domain as an improved switch for the regulation of heterologous proteins. Nucleic Acids Res. 23: 1686-1690

17. Versteeg R, Noordermeer IA, Krüse-Wolters KM, Ruiter DJ and Schrier PI (1988) c-Myc downregulates class I HLA expression in human melanomas. EMBO J. 7: 1023-1029
18. Kashkar H, Krönke M and Jürgensmeier JM (2002) Defective Bax activation in Hodgkin B-cell lines confers resistance to staurosporine-induced apoptosis. Cell Death Differ. 9: 750-757

19. Sedmak JJ and Grossberg SE (1977) A rapid, sensitive, and versatile assay for protein using Coomassie brilliant blue G250. Anal. Biochem. 79: 544-552

20. Stennicke HR and Salvesen GS (1997) Biochemical characteristics of caspases-3, -6, -7, and -8. J. Biol. Chem. 272: 25719-25723

21. Rotonda J, Nicholson DW, Fazil KM, Gallant M, Gareau Y, Labelle M, Peterson EP, Rasper DM, Ruel R, Vaillancourt JP, Thornberry NA and Becker JW (1996) The three-dimensional structure of apopain/CPP32, a key mediator of apoptosis. Nat. Struct. Biol. 3: 619-625

22. Nicholson DW, Ali A, Thornberry NA, Vaillancourt JP, Ding CK, Gallant M, Gareau Y, Griffin PR, Labelle M and Lazebnik YA (1995) Identification and inhibition of the ICE/CED-3 protease necessary for mammalian apoptosis. Nature 376: 37-43

23. Talanian RV, Quinlan C, Trautz S, Hackett MC, Mankovich JA, Banach D, Ghayur T, Brady KD and Wong WW (1997) Substrate specificities of caspase family proteases. J. Biol. Chem. 272: 9677-9682

24. Garcia-Calvo M, Peterson EP, Leiting B, Ruel R, Nicholson DW and Thornberry NA (1998) Inhibition of human caspases by peptide-based and macromolecular inhibitors. J. Biol. Chem. 273: 32608-32613

25. Gu Y, Sarnecki C, Aldape RA, Livingston DJ and Su MS (1995) Cleavage of poly(ADP-ribose) polymerase by interleukin-1 beta converting enzyme and its homologs TX and Nedd-2. J. Biol. Chem. 270: 18715-18718

26. Lassus $P$, Opitz-Araya $X$ and Lazebnik $Y$ (2002) Requirement for caspase-2 in stress-induced apoptosis before mitochondrial permeabilization. Science 297: 1352-1354

27. Markwardt F, Drawert J and Walsmann P (1974) Synthetic low molecular weight inhibitors of serum kallikrein. Biochem. Pharmacol. 23: 2247-2256

28. Han Z, Hendrickson EA, Bremner TA and Wyche JH (1997) A sequential twostep mechanism for the production of the mature p17:p12 form of caspase-3 in vitro. J. Biol. Chem. 272: 13432-13436

29. Kagaya S, Kitanaka C, Noguchi K, Mochizuki T, Sugiyama A, Asai A, Yasuhara $N$, Eguchi $Y$, Tsujimoto $Y$ and Kuchino $Y$ (1997) A functional role for death proteases in s-Myc- and c-Myc-mediated apoptosis. Mol. Cell. Biol. 17: 6736-6745

30. Elliott K, Ge K, Du W and Prendergast GC (2000) The c-Myc-interacting adaptor protein Bin1 activates a caspase-independent cell death program. Oncogene 19: 4669-4684

31. McCarthy NJ, Whyte MK, Gilbert CS and Evan GI (1997) Inhibition of Ced-3/ ICE-related proteases does not prevent cell death induced by oncogenes, DNA damage, or the Bcl-2 homologue Bak. J. Cell. Biol. 136: 215-227

32. Brunet $\mathrm{CL}$, Gunby RH, Benson RS, Hickman JA, Watson AJ and Brady G (1998) Commitment to cell death measured by loss of clonogenicity is separable from the appearance of apoptotic markers. Cell Death Differ. 5: $107-115$

33. Davidson FF and Steller H (1998) Blocking apoptosis prevents blindness in Drosophila retinal degeneration mutants. Nature 391: 587-591

34. Johnson MD, Xiang H, London S, Kinoshita Y, Knudson M, Mayberg M, Korsmeyer SJ and Morrison RS (1998) Evidence for involvement of Bax and p53, but not caspases, in radiation-induced cell death of cultured postnatal hippocampal neurons. J. Neurosci. Res. 54: 721-733

35. Gobeil S, Boucher CC, Nadeau D and Poirier GG (2001) Characterization of the necrotic cleavage of poly(ADP-ribose) polymerase (PARP-1): implication of lysosomal proteases. Cell Death Differ. 8: 588-594

36. Robertson JD, Enoksson M, Suomela M, Zhivotovsky B and Orrenius S (2002) Caspase-2 acts upstream of mitochondria to promote cytochrome $c$ release during etoposide-induced apoptosis. J. Biol. Chem. 277: 29803-29809

37. Guo Y, Srinivasula SM, Druilhe A, Fernandes-Alnemri T and Alnemri ES (2002) Caspase-2 induces apoptosis by releasing proapoptotic proteins from mitochondria. J. Biol. Chem. 277: 13430-13437

38. O'Reilly LA, Ekert P, Harvey N, Marsden V, Cullen L, Vaux DL, Hacker G, Magnusson C, Pakusch M, Cecconi F, Kuida K, Strasser A, Huang DC and Kumar S (2002) Caspase-2 is not required for thymocyte or neuronal apoptosis even though cleavage of caspase-2 is dependent on both Apaf- 1 and caspase9. Cell Death Differ. 9: 832-841

39. Park IC, Park MJ, Choe TB, Jang JJ, Hong SI and Lee SH (2000) TNF-alpha induces apoptosis mediated by AEBSF-sensitive serine protease(s) that may 
involve upstream caspase-3/CPP32 protease activation in a human gastric cancer cell line. Int. J. Oncol. 16: 1243-1248

40. Stefanis L, Troy CM, Qi H and Greene LA (1997) Inhibitors of trypsin-like serine proteases inhibit processing of the caspase Nedd-2 and protect PC12 cells and sympathetic neurons from death evoked by withdrawal of trophic support. J. Neurochem. 69: 1425-1437

41. Dong Z, Saikumar P, Patel Y, Weinberg JM and Venkatachalam MA (2000) Serine protease inhibitors suppress cytochrome c-mediated caspase- 9 activation and apoptosis during hypoxia-reoxygenation. Biochem. J. 347 (Part 3): 669-677

42. Rideout HJ, Zang E, Yeasmin M, Gordon R, Jabado O, Park DS and Stefanis L (2001) Inhibitors of trypsin-like serine proteases prevent DNA damage-induced neuronal death by acting upstream of the mitochondrial checkpoint and of p53 induction. Neuroscience 107: 339-352

43. Leist $M$ and Jaattela $M$ (2001) Four deaths and a funeral: from caspases to alternative mechanisms. Nat. Rev. Mol. Cell Biol. 2: 589-598

44. Foghsgaard L, Wissing D, Mauch D, Lademann U, Bastholm L, Boes M, Elling F, Leist M and Jaattela M (2001) Cathepsin B acts as a dominant execution protease in tumor cell apoptosis induced by tumor necrosis factor. J. Cell. Biol. 153: $999-1010$

45. Guicciardi ME, Miyoshi H, Bronk SF and Gores GJ (2001) Cathepsin B knockout mice are resistant to tumor necrosis factor-alpha-mediated hepatocyte apoptosis and liver injury: implications for therapeutic applications. Am. J. Pathol. 159: 2045-2054

46. Navab R, Chevet E, Authier F, Di Guglielmo GM, Bergeron JJ and Brodt $P$ (2001) Inhibition of endosomal insulin-like growth factor-I processing by cysteine proteinase inhibitors blocks receptor-mediated functions. J. Biol. Chem. 276: 13644-13649

47. Darmon AJ, Nicholson DW and Bleackley RC (1995) Activation of the apoptotic protease CPP32 by cytotoxic T-cell-derived granzyme B. Nature 377: 446-448

48. Trapani JA, Davis J, Sutton VR and Smyth MJ (2000) Proapoptotic functions of cytotoxic lymphocyte granule constituents in vitro and in vivo. Curr. Opin. Immunol. 12: 323-329
49. Sutton VR, Davis JE, Cancilla M, Johnstone RW, Ruefli AA, Sedelies K Browne KA and Trapani JA (2000) Initiation of apoptosis by granzyme B requires direct cleavage of bid, but not direct granzyme B-mediated caspase activation. J. Exp. Med. 192: 1403-1414

50. Heibein JA, Goping IS, Barry M, Pinkoski MJ, Shore GC, Green DR and Bleackley RC (2000) Granzyme B-mediated cytochrome $c$ release is regulated by the Bcl-2 family members bid and Bax. J. Exp. Med. 192: 1391-1402

51. Waterhouse NJ, Finucane DM, Green DR, Elce JS, Kumar S, Alnemri ES Litwack G, Khanna K, Lavin MF and Watters DJ (1998) Calpain activation is upstream of caspases in radiation-induced apoptosis. Cell Death Differ. 5 : 1051-1061

52. Hiwasa T, Sawada T and Sakiyama S (1990) Cysteine proteinase inhibitors and ras gene products share the same biological activities including transforming activity toward $\mathrm{NIH} 3 \mathrm{~T} 3$ mouse fibroblasts and the differentiationinducing activity toward PC12 rat pheochromocytoma cells. Carcinogenesis 11: $75-80$

53. Hegde R, Srinivasula SM, Zhang Z, Wassell R, Mukattash R, Cilenti L, DuBois G, Lazebnik Y, Zervos AS, Fernandes-Alnemri T and Alnemri ES (2001) Identification of $\mathrm{Omi} / \mathrm{HtrA} 2$ as a mitochondrial apoptotic serine protease that disrupts IAP-caspase interaction. J. Biol. Chem 277: 432-438

54. Verhagen AM, Silke J, Ekert PG, Pakusch M, Kaufmann H, Connolly LM, Day CL, Tikoo A, Burke R, Wrobel C, Moritz RL, Simpson RJ and Vaux DL (2001) $\mathrm{HtrA} 2$ promotes cell death through its serine protease activity and its ability to antagonise inhibitor of apoptosis proteins. J. Biol. Chem 277 $445-454$

55. Martins LM, laccarino I, Tenev T, Gschmeissner S, Totty NF, Lemoine NR, Savopoulos J, Gray CW, Creasy CL, Dingwall C and Downward J (2001) The serine protease Omi/HtrA2 regulates apoptosis by binding XIAP through a Reaper-like motif. J. Biol. Chem 277: 439-444

56. van Loo G, van Gurp M, Depuydt B, Srinivasula SM, Rodriguez I, Alnemri ES, Gevaert K, Vandekerckhove J, Declercq W and Vandenabeele P (2002) The serine protease $\mathrm{Omi} / \mathrm{HtrA} 2$ is released from mitochondria during apoptosis. Omi interacts with caspase-inhibitor XIAP and induces enhanced caspase activity. Cell Death Differ. 9: 20-26 